\title{
"We Grandmothers Know Plenty": Breastfeeding, complementary feeding and the multifaceted role of grandmothers in Malawi ${ }^{\text {th }}$
}

\author{
Rachel Bezner Kerr ${ }^{\mathrm{a}, *}$, Laifolo Dakishoni ${ }^{\mathrm{b}}$, Lizzie Shumba ${ }^{\mathrm{b}}$, \\ Rodgers Msachi ${ }^{\mathrm{b}}$, Marko Chirwa ${ }^{1}$ \\ a Department of Geography, The University of Western Ontario, 1151 Richmond Street N., SSC 2409, London, Ontario, Canada N6A 5C2 \\ ${ }^{\mathrm{b}}$ Ekwendeni Hospital, Ekwendeni, Malawi
}

Available online 21 December 2007

\begin{abstract}
This paper has two purposes: first of all, we examine grandmothers' role and views of child feeding practices in northern Malawi, and their influence on younger women's practices. Secondly, we consider the implications of these findings for health promotion activities and models of health education. Data were collected from semi-structured interviews, focus groups and a participatory workshop. Findings demonstrate that, to address child feeding practices which have an effect on nutrition, attention must be paid to the broader context that influences child nutrition, including extended family relations. Paternal grandmothers have a powerful and multifaceted role within the extended family in northern Malawi, both in terms of childcare and in other arenas such as agricultural practices and marital relations. Grandmothers often differ in their ideas about early child feeding from conventional Western medicine. Some practices have existed in the area at least since colonial times, and have strong cultural significance. Despite the important integrated role, older women have within households and communities in this part of Malawi, hospital personnel often have disparaging and paternalistic attitudes towards 'grannies' and their knowledge. Health education rarely involves grandmothers, and even if they are involved, their perspectives are not taken into consideration. Hospital staff often reject grandmother knowledge as part of a broader modernization paradigm which views 'traditional knowledge' as backward. Grandmothers view current child health conditions within a broader context of changing livelihood conditions and a high prevalence of HIV/ AIDS. The paper concludes by discussing the challenges of involving grandmothers in health education, and the difficulties of incorporating local knowledge into a medical system that largely rejects it.
\end{abstract}

(c) 2007 Elsevier Ltd. All rights reserved.

Keywords: Malawi; Child nutrition; Grandmothers; Health education; Child health; Breastfeeding

\footnotetext{
This work was carried out with the aid of a grant from the International Development Research Centre, Ottawa, Canada.

* Corresponding author. Tel.: +1 519661 2111; fax: +1 519661 3750 .

E-mail addresses: rbeznerkerr@uwo.ca (R. Bezner Kerr), soilsandfood@sdnp.org.mw (L. Dakishoni), soilsandfood@sdnp. org.mw (L. Shumba), soilsandfood@sdnp.org.mw (R. Msachi).

1 Deceased.
}

\section{Introduction}

This paper uses a case study of an agriculture and nutrition project in Malawi to understand the role of grandmothers in influencing child nutrition, and the implications and challenges of involving them in a nutrition education program. The term grandmothers is used primarily to refer to the paternal grandmother of a child. 
The paper explores the multifaceted ways in which grandmothers affect child nutrition, and dimensions of power and knowledge that interact with this role. A discussion of the project's efforts to involve grandmothers in nutrition education will highlight the challenges of trying to incorporate this multifaceted role into a public health intervention. It is argued that health education needs to take a more holistic approach to understanding child nutrition within a broader context of kin relationships.

\section{Early child feeding: scientific recommendations and Malawian context}

Current public health policy encourages mothers to exclusively breastfeed (EBF) their child for the first 6 months of their child's life, for nourishment and protection from infections (Coovadia et al., 2007; WHO \& UNICEF, 2002). This recommendation holds even in countries with high rates of HIV, due to evidence that the benefits of exclusive breastfeeding outweigh the risk of HIV transmission, and some evidence that the rate of HIV transmission may be reduced with exclusive breastfeeding (Coovadia et al., 2007; Coutsoudis, Kuhn, Pillay, \& Coovadia, 2002; Iliff et al., 2005; WHO, 2003).

Child malnutrition rates have been high in Malawi for over two decades (NSO \& Macro, 1994, 2001; NSO \& ORC Macro, 2005). Approximately half of Malawian under 5 years of age (U5) children are stunted, with peak levels occurring between 12 and 24 months of age. There are serious child health and survival consequences from this level of malnutrition (Pelletier, 1994). Improvements in EBF rates and in complementary feeding methods could reduce morbidity and mortality rates currently experienced in Malawi, where the U5 mortality rate is 183 deaths per 1000 live born children (UNICEF, 2005).

Current EBF rates are estimated at 53\% for children under 6 months in Malawi, up from 45\% in 2000 (NSO \& ORC Macro, 2005). Other studies report much lower EBF rates (MSIS, 1996; Shrestha, 1989; Vaahter et al., 2001). The 1992 DHS reported that over $90 \%$ of infants under 4 months were not EBF (Madise \& Mpoma, 1997). The high recent EBF rates reported by the recent DHS study in Malawi may be due to national efforts to promote EBF, which may have led to reporting bias. Cross-sectional surveys are also less effective at capturing EBF, since there is often poor recall of occasional introduction of liquids other than breastmilk. A recent longitudinal study reported EBF rates of $19 \%, 8 \%$, $2 \%$ and $0 \%$ at ages 1, 2, 3 and 4 months, respectively (Vaahter et al., 2001).
In the context of an estimated $14 \%$ HIV prevalence rate (UNAIDS, 2006), the promotion of EBF becomes more complex. Some public health programs in Malawi are now recommending that if a pregnant women is $\mathrm{HIV}+$, she receive counseling to make an 'informed choice', in order to understand the risks and benefits of various feeding options (De Cock et al., 2000). This issue is relevant when considering the broader social context in which a woman is making feeding choices.

Earlier research by the authors indicates that there were four primary foods/liquids introduced to infants prior to 6 months (presented in order of introduction): mzuwula (a type of herbal infusion), water, dawale (another herbal infusion) and porridge (Bezner Kerr, Berti, \& Chirwa, 2007). In $78 \%$ of the 86 cases where $m z u$ wula was introduced, the paternal grandmother made the decision while in $30 \%$ of the 173 cases where water or dawale water was introduced, the paternal grandmother decided, and the grandmother decided to give dawale in $56 \%$ of the 41 cases where dawale alone was introduced. Grandmothers also decided to introduce porridge in $21 \%$ of the 230 cases where it was introduced prior to 6 months (Bezner Kerr et al., 2007). These findings will be discussed in light of the qualitative data presented about the role and perspectives of grandmothers.

\section{Child nutrition and health education models}

In the last decade, there has been progress in understanding the nutritional needs of young children (WHO, 1998). Child nutrition is increasingly understood within a broader framework of "care", which takes into account pregnancy, lactation, feeding practices, food preparation, care during illness and social stimulation (Engle, Menon, \& Haddad, 1999). There have been improvements in understanding the biological and social causes of malnutrition, and some success in improving child nutrition through promotion of changes in early child feeding practices (Caulfield, Huffman, \& Piwoz, 1999; Pelto, Dicken, \& Engle, 1999; Samba, Sy, Ntiru, \& Diene, 1999; WHO, 1998). The need to integrate an understanding of care within nutrition education programs has been emphasized in the nutritional sciences (Engle, Bentley, \& Pelto, 2000). Two critical aspects of this model are the caregiver and the decision-maker, that is, who is providing childcare and who is involved in childcare decisions. A review of studies on complementary feeding showed that children's growth, maternal knowledge and feeding practices can be improved through integrated programs (Caulfield et al., 1999). 
Integrated programs that give attention to gender, however, usually focus on young mothers, and the dynamics of intergenerational conflicts or the role of grandmothers are rarely mentioned.

The nutrition educational model that dominates in public health is primarily based on a social psychological model, one that assumes that individuals act rationally, evaluate information and make nutrition and health choices with limited outside influence (Yoder, 1997). Most nutrition and health educational approaches also focus on the individual caregiver, and assume that as mothers receive new information about childcare, they will modify their behavior (Aubel, Toure, \& Diagne, 2004; Lee \& Garvin, 2003; Lupton, 1995; Yoder, 1997). Individual caregivers, usually assumed to be the biological mother, are often viewed as passive receptors of knowledge, with communication flows going in one direction from experts to lay people (Lee \& Garvin, 2003). By focusing on mothers of reproductive age, nutrition education programs ignore the important role of the extended family and community in early child development. This educational model also ignores the agency and knowledge of caregivers and their families, and their ability to adapt information to their own social context (Lee \& Garvin, 2003). A review of nutrition education programs that use this social psychological model notes that this approach is "seldom effective in the long term" (Allen \& Gillespie, 2001, 75). Although widely critiqued, this model continues to be widely used in public health and nutrition education.

An alternative approach to nutrition education is one of transformative learning, or empowerment education which uses a systems approach to assess the broader context that influences health outcomes. Transformative learning emphasizes dialogue and problem-solving to increase knowledge (Aubel \& Sihalathavong, 2001; Kent, 1988; Lee \& Garvin, 2003). This paper argues that the approach using dialogue and problem-solving approach is more appropriate in the context of northern Malawi given the role of grandmothers, their different knowledge base and contrasting views about child nutrition.

\section{Experiences with health education on child nutrition in Sub-Saharan Africa}

Studies in several African countries indicate that grandmothers often make critical decisions about early child feeding practices and can have a significant impact on child nutritional status (Aubel et al., 2004; Davies-Adetugbo, 1997; Macharia, Kogi-Makau, \&
Muroki, 2004; Sear, Mace, \& McGregor, 2000). Most health education carried out in Sub-Saharan Africa focuses on the mothers of young children (Aubel et al., 2004; Lee \& Garvin, 2003; Waisbord, 2001). Few health education programs have addressed the role that grandmothers play in decision-making and childcare activities (Aubel \& Sihalathavong, 2001; Aubel et al., 2004; van Esterik, 1995). One NGO, 'The Grandmother Project', has spearheaded a transformative, participatory health education approach to integrating grandmothers in nutrition education (Aubel, 2004). The Grandmother Project (GP) initiated a nonformal health education project in Laos with UNICEF and the WHO which built on grandmothers' role and knowledge, while integrating key new health practices. After 4 months, the number of grandmothers (175, aged 45-75 years) who advised mothers to give 'lots of fluids' to a child with diarrhea increased from 30 to 74\% (Aubel \& Sihalathavong, 2001). A recent study in Senegal by the GP and the Christian Children's Fund involved grandmothers in nutrition education focused on pregnancy advice, breastfeeding and complementary feeding of young children (Aubel et al., 2004). In this case, the health education model was that of transformative learning, which involved grandmothers and mothers actively assessing their situation and coming up with strategies to improve child nutrition. Problem-posing songs and stories were used to generate discussion during week-long workshops with grandmothers and women of reproductive age. The study found significant positive changes in reported complementary feeding practices and grandmothers' advice after 9 months of intervention. For example, out of 134 grandmothers pre-intervention, 29\% of grandmothers reported telling women to give the first complementary porridge at 6 months, while out of 150 grandmothers, $92 \%$ reported giving women the same advice following the intervention, and $93 \%$ of women of reproductive age reported receiving this advice post-intervention.

No known programs in Malawi at the time of writing have integrated grandmothers actively into nutrition education programs. Hotz and Gibson $(2001,2005)$ have carried out several nutrition interventions to improve complementary feeding practices in Malawi. The approach used involved pilot testing different recipes that would increase the nutritional value of complementary foods and promoting a series of 'messages' for mothers about ways to improve complementary feeding (Hotz \& Gibson, 2005). While integrating local cooking practices into their messages, the nutrition educational approach appears to be primarily an information transfer 
model focused on the mother (Lee \& Garvin, 2003). Most of the large nutrition programs in Malawi take a similar approach, using behavior change communication or social marketing approaches to impart messages to women of childbearing age about early child nutrition. ${ }^{2}$ Some notable exceptions include Save the Children and Action against Hunger, both of which emphasize a more holistic approach, including addressing food security, and household and community capacity building. ${ }^{3}$ The Positive Deviance/Hearth model promoted by USAID also integrates local knowledge and a dialogue approach to addressing child nutrition, but the focus remains on the mothers of young children.

\section{Methods}

\section{Study area}

This research took place in a rural area of northern Malawi, $20 \mathrm{~km}$ north of Ekwendeni, a town of approximately 20,000 people. Most of the population in the region are smallholder farmers, with maize as their primary staple crop, harvested in May-June after the single annual rainy season. Other important crops include tobacco as a major cash crop, cassava, beans, groundnuts and sweet potatoes. The research was conducted as part of a participatory agriculture and nutrition project, which began in 2000 and as of 2007 works with over 5000 smallholder farm households in the region. The project uses an action research or transformative educational approach, integrating grandmothers and other people with critical social influences on child nutrition into educational activities (Bezner Kerr \& Chirwa, 2004).

\section{Data collection}

This paper reports on qualitative data from a larger research project which combined qualitative, quantitative and participatory action research methods. An earlier paper presents the quantitative survey findings on early child feeding patterns and decision-makers (Bezner Kerr et al., 2007). This paper is developed from research generated from three primary types of data collection: (1) semi-structured interviews; (2) focus groups; and (3) a participatory workshop. The

\footnotetext{
${ }^{2}$ See for example, the description of UNICEF's approach on their website: http://www.unicef.org/infobycountry/malawi_2424.html, accessed 31.05.07.

${ }^{3}$ See for example of a more holistic approach: http://www. actionagainsthunger.org/programs/malawi.html.
}

research was carried out over a 3-year period and was iterative, with qualitative research informing the design of a survey, survey results leading to further qualitative research, research results presented at a workshop and leading to further inquiry. The three research activities are described below. All research was carried out in the Ekwendeni Hospital catchment area with a population of approximately 70,000 people. Specific sampling methods of different research activities in these villages are described below.

\section{Semi-structured interviews and focus groups on childcare and feeding practices}

A stratified purposeful sampling method was used to select key informants knowledgeable about childcare and feeding practices and representing different groups in the villages (i.e., older women, traditional medicine practitioners, young women and food insecure households) (Patton, 1990). Semi-structured interviews on childcare and feeding practices were carried out with 21 informants. Questions were developed by the researchers based on pre-testing interviews. After initial analysis and review of the data, two follow-up focus groups were conducted, one with a group of four older women considered to be knowledgeable about child feeding, and the other with a group of eight younger women with young children. Key hospital staff in breastfeeding education and maternal and child health care was interviewed. A team of researchers carried out the interviews and focus groups: the five authors, as well as a Canadian nutritionist. The team worked in pairs to carry out the interviews, with one person interviewing, the other translating or taking notes. Informed consent was obtained prior to all interviews. We recorded all interviews except for the hospital staff interviews, and the tapes were transcribed and translated into English.

\section{Participatory workshop}

Using a participatory action research model, the research team held a workshop to synthesize, share and critique initial research findings with community members and plan a nutrition education program. The team organized a 3-day participatory workshop in 2003, after preliminary analysis of the qualitative and survey data. Research members selected participants in order to build a representative group from the community, including grandmothers, food insecure farmers, young mothers, community leaders and farmers involved in the project. The team also selected hospital staff based on experience carrying out nutrition education on breastfeeding and complementary feeding. Five themes 
for the workshop were identified: breastfeeding, early child feeding, legume recipes, family cooperation and traditional knowledge. The workshop consisted of presentations (including dramas and songs) on the different themes, group discussions, and planning for follow-up activities.

\section{Semi-structured interviews on traditional herbal infusion practices and beliefs}

After further data analysis, the research team carried out follow-up interviews in 2004. The first author developed the interview guide and the other four authors refined the guide. Nine people from three villages and three categories were purposefully selected and interviewed. These groups were men, younger married couples, and older women. Each interview took approximately $1 \mathrm{~h}$, and was tape-recorded.

\section{Data analysis}

A grounded theory approach to qualitative data analysis was used to examine the interviews for trends, differences and common themes (Ryan \& Bernard, 2000). An initial coding system was developed based on major concepts employed in the study (e.g., 'caregiver' or 'moto', a disease with symptoms of coughing and low weight), and the data were analysed using methods such as data summaries, finding themes and patterns, clustering and data displays (Miles \& Huberman, 1994). Emic concepts (that is, phenomena based on the participants' understanding) such as 'mzuwula' were identified and explored further in follow-up interviews (Maxwell, 1992). Efforts to ensure validity and reliability of the data included presentation of the results to key informants and triangulation with multiple methods (Gilchrist, 1992).

\section{Results}

\section{Role of the grandmother in early child feeding and care}

Interviews and focus groups provided evidence that the paternal grandmother is actively involved in care of the pregnant mother and early childcare. The grandmother is present soon after the birth of the child, providing clothes and helping the mother to establish breastfeeding. Women in focus groups and interviews indicated that grandmothers are also key decisionmakers in deciding when to introduce foods other than breastmilk to infants. The four most common foods introduced to infants under 6 months, as noted above, are mzuwula (a root infusion), water, dawale (another herbal infusion) and porridge. Sometimes dawale is combined with either water or porridge.

The root infusion mzuwula is often the first nonbreastmilk substance given to infants, in order to provide protection against an illness called moto. Some of the signs of moto are fast breathing, coughing, white mucus and low weight for the child. Grandmothers and other elders of the village identify if a child is suffering from moto. If a child has died, moto is suspected if white mucus comes out of the nostrils (Bezner Kerr, 2006). Moto is thought to be caused by sexual impropriety within the household or others in the village. Grandmothers are the primary source of knowledge for preparation of mzuwula. The mother-in-law of the respondent - that is, the paternal grandmother - was the most common person deciding to give mzuwula to babies. As one informant explained:

"A type of root water is given to babies when they are first born. The name of the plant is mzuwula. The mother-in-law [paternal grandmother] collects the root, but if she does not then the mother does. The mother-in-law cuts it into small pieces, puts it into a pot, boils it and cools it. Then she bathes the baby. This is done for six months. My baby is six months and is still being bathed. Some people do it for a year or more, others only for six months. Once my mother-in-law teaches me, I bathe the baby every day... and I give root water to the baby three times a day, one spoonful each time.

[Question asked: why do you give the baby root water and bathe the baby in root water?]. We believe traditionally that when a baby is born, you should bathe it, if you don't, prostitutes in the village might make the baby get sick and die. The medicine protects the baby from getting sick."

Younger woman, Child Feeding Practices Qualitative Interview3, August 8, 2001.

A second key concept for grandmothers is that women often have insufficient milk when breastfeeding, and babies may need water, dawale or porridge to supplement breastmilk. A child can be born 'with hunger' and cries until they receive water or porridge. Grandmothers are often involved in determining if a child is getting insufficient milk from breastfeeding. As one focus group of older women explained:

"[If] a child is born and is crying due to stomachache then we say the child is born with hunger, then we give dawale, which is water. Some do 
add medicine to the dawale and these are the ones with stomachaches. Then she drinks; if she continues to cry you also give porridge and so when [you] give porridge and the child sleeps you say ummh! This child was born with hunger! Now that she has slept they continue feeding the child with porridge"

Older woman, Child Feeding Focus Group 1, February 7, 2002.

Grandmothers are sometimes involved in decisions about ending breastfeeding. In some cases, the child was given to the wife's mother-in-law when the breastfeeding period was over, a practice that they cited as a traditional one, and one that has been noted in earlier anthropological literature in the region (Barnes, 1959; Read, 1959). At least two cases were found of the child going to live with his paternal grandmother after he was weaned. In several cases grandmothers suggested that breastfeeding be ended because it interfered in marital relations.

Grandmothers are also very often caregivers of young children, once the child is about 9 months of age, or when the child begins to crawl. According to qualitative interviews, if mothers have to go to the market, the field or the hospital, they often leave their toddlers in the care of their mother-in-law. This caregiving role means that grandmothers influence the frequency with which young children are fed, particularly during the rainy season when mothers are working long hours in the fields. In one participatory workshop where frequency of child feeding was discussed, it became clear that mothers and grandmothers often disagree about who is responsible for feeding children the midday meal. This issue will be discussed below in light of project attempts to increase frequency of feeding.

\section{Grandmothers' advisor role in marriage and child illness}

According to interviews, focus groups and observation, grandmothers are considered to be important sources of knowledge and advice in many arenas of life. They often live next door to a married couple, provide seed to the couple when they first get married, and provide advice on pregnancy and care of young children. Grandmothers pass information about child nutrition to other older women. Mothers have considerable influence over their sons' marital relationship. If a mother felt it necessary, she could recommend divorce for her sons. A mother-in-law could take a child away from a mother if she felt the child was not being cared for properly. Their powerful influence means that many young mothers obey their mothers-in-law on child feeding suggestions even if they have been told differently by the hospital. During one focus group discussion, younger women stated that older women were the people with more power or strength over childcare and feeding decisions - more than the mother and more than the hospital. When a mother is thought to be feeding a child poorly, older women will say things like "you are starving the child, bring him here". They would then feed the child. Younger women expressed feelings of helplessness in trying to implement practices at variance with their mothers-in-law.

During the participatory workshop, grandmothers expressed strong views that the current condition of poor health and nutrition of young children in the villages was related to broader changes in sexual practice and a lowering of respect for elders and traditional practices. One key practice that they strongly felt has been ignored is that of a husband and wife abstaining from sexual intercourse for 1 year after the birth of a child. Many older women stated unequivocally that the reason that child malnutrition was high in their communities was because young people, particularly women, no longer followed this practice. They felt if a couple had sexual intercourse during the first year of a child's life, the child would get moto, an illness that manifested itself through loss of weight and coughing. Not following this practice was part of a broader trend in their communities, in which people did not respect traditional ways:

"Our children did not used to die so often, we did not have this problem of malnutrition. It is because you young women do not respect the old ways, you are busy giving in to your husbands, that is the cause of the problem."

Paraphrased from comment in chiTumbuka by an older woman during a participatory nutrition workshop, February 2003.

Other older women stood up and stated that the lightness of young children, which can be tested by lifting a child, is caused by moto, and that it is a problem of marital infidelity or promiscuity. Older women made similar statements in semi-structured interviews. Younger women remained silent during the outspoken speeches led by the older women and spoke little throughout the workshop. It was clear from the dynamics during the workshop and in focus group discussions and interviews with younger women that older women remain a formidable force in households and communities, but that their influence has shifted and lessened, 
in part due to conflicting messages and power dynamics between older women and the hospital.

While not the focus of the workshop, the issue of HIV/AIDS was 'behind the scenes' in many older people's narratives about higher rates of adult mortality in communities. Older women felt that adult and child mortality was due to the fact that young people no longer respect traditional ways, particularly in terms of postpartum sexual activity. Hospital staff contradicted this point by noting that in the past, if a husband could not have sex with his wife, he would go to another woman. Thus, by promoting this traditional postpartum abstinence, HIV/AIDS was inadvertently also being promoted. The 'cause' of HIV/AIDS and child malnutrition is being contested in these clashing perspectives, but with an information transfer model of public health education, the views of grandmothers are rarely heard or understood.

\section{The role of the hospital in child feeding decisions}

The hospital has been promoting exclusive breastfeeding as part of their maternal and child health education. They became a registered "Baby Friendly Hospital" in 2000, an initiative that has been promoted by UNICEF and the WHO to promote exclusive breastfeeding for the first 6 months of life. Exclusive breastfeeding is actively promoted at all the maternal and child mobile clinics operated on a monthly basis in the villages. Posters, murals and signs throughout the hospital promote the EBF policy.

In interviews, nurses responsible for the promotion of EBF named 'grannies', or the mother-in-law as the main barrier to improvement of exclusive breastfeeding rates in the villages. They told stories of grandmothers bringing root water or porridge secretly to the hospital and force-feeding it to young babies. Hospital staff were somewhat derisive of 'grannies' and expressed frustration with traditional views of older women. Local villagers were very aware that hospital staff wanted them to breastfeed their child exclusively for the first 6 months. Since the hospital is the only source of formal health care available in the region, many women were afraid to admit that they introduced foods at any earlier age, because they did not want to antagonize hospital staff. A study carried out in a central Malawi village on pregnancy found that women went to antenatal clinics primarily to prevent clinical nurses from chastising them during delivery (Helitzer-Allen, Kendall, \& Wirima, 1997). One young woman in a focus group discussion noted the value of following hospital recommendations, to avoid being chastised by hospital staff, adding that she had not done so:
"I was also advised at the hospital... about six months [exclusive breastfeeding] but I introduced other foods earlier because there was a little food in her body. I can't know but it is good [sic] to follow the hospital recommendation because when we face problems we go there where they don't like what we do here, so to obey them it is good because they will tell you 'because you are disobedient that is why all these things have happened to you'."

\section{Younger woman in focus group discussion, February 8, 2002.}

During other interviews women expressed fear of hospital disapproval, should they reveal that they have not exclusively breastfed. All of these women admitted that in fact they had not breastfed exclusively, but had introduced porridge and traditional herbal infusions. Some stated that they themselves chose to give other foods to infants, while others indicated that their mothers-in-law or another older woman had insisted that they give them other foods. Younger women in one focus group talked about the conflict between the hospital and older women, noting that they felt caught in between, with little choice but to obey older women while not revealing their actual practices to the hospital:

"You can listen from the hospital, but when the child cries, the mother-in-law will ask you to give them [food] and they will prepare and feed the child porridge and then tomorrow they will do the same thing."

\section{Younger woman in focus group discussion, February 7, 2002.}

In 2004, the hospital implemented a large child survival program in the catchment area focused on infant care, and focused much of their nutrition education on older women. Almost all older women in the region attended education classes held by the hospital, and were told that they should no longer give children traditional herbal infusions such as mzuwula or dawale. Hospital staff even warned grandmothers that bathing a newborn baby in a herbal infusion could cause the child to have pneumonia. This program has made villagers even more cautious about admitting to early introduction of other foods/liquids to infants. During public meetings with the hospital, some community leaders have made sweeping statements - for instance, that no one follows the traditional practices of mzuwula or dawale anymore due to the hospital training. In the participatory workshop, however, older women argued 
that herbal infusions were required to protect infants from moto and to ensure good growth. The qualitative and quantitative studies carried out 1-3 years previously, reported above and in earlier publications (Bezner Kerr et al., 2007), show high rates of early introduction of other substances to infants. Based on the these findings, we suggest that the statements made publicly by community leaders reflect the power that the hospital plays in providing health care to the communities, and do not reflect actual practice. EBF has been actively promoted in the communities for 6 years using similar techniques, and research so far shows limited compliance. Further studies will be needed, however, to substantiate these claims.

\section{'Jenda', agriculture and frequent feeding}

Following the participatory nutrition workshop in 2003, the SFHC project initiated a pilot participatory nutrition education program using the transformative educational model, with 'village nutrition teams'. Initially working in seven villages, the program has expanded to over 100 villages and works with over 5000 farming households. Village nutrition teams work in village areas, which are made up of 12-20 villages. The teams are made up of older women, younger women with young children and men. They carry out house visits to families known to have severely malnourished children and have 'recipe days' to promote healthy foods for young children, through performing dramas/plays. They chose four themes to emphasize in their nutrition education: exclusive breastfeeding, legume recipes for children over 6 months, family cooperation and frequent feeding of young children.

The village nutrition teams encountered a lot of resistance from men and older women on the theme of family cooperation, often translated as 'jenda' (that is, gender) by villagers and SFHC staff. Often times both villagers and SFHC staff interpreted 'jenda' to mean that the entire division of labor between men and women had to be altered. In one meeting where family cooperation was discussed, men shouted out that they could not be expected to carry water or cook. Older women also expressed strong opinions that this 'jenda' would lead to younger women being lazy and doing nothing around the house. Younger women reported that if their husbands helped with childcare and feeding, their mothers-in-law complained.

Some mothers also suggested that their mothers-inlaw refused to take any advice about the importance of frequent feeding young children 6-18 months old. This issue was raised again in another meeting that year. Older women stated that daughters-in-law tend to be 'lazy' and need to be encouraged to work hard, and if they were left to prepare the food for their grandchildren, it made the young mothers even more lazy. They also suggested that they resented being given additional tasks. Their resistance to additional feeding of young children, and their tendency to blame younger women for this situation, is in part linked to an increased adult mortality from HIV/AIDS prevalence and the subsequent added workload in their own lives.

Grandmothers are central figures in agricultural production, social knowledge and child feeding decisions. Their centrality in all three areas, and the linkages between these three areas, underlies the importance both of involving them in nutrition education, understanding their perspective, and understanding how agriculture and health are interrelated in Malawi. Grandmothers in this part of the world are usually farmers, and their role in food production is linked to their roles in childcare and feeding. For example, one grandmother interviewed had a sweet potato field, which she frequently cultivated for giving snacks to her grandchildren. In another interview, a grandmother indicated that she chose to grow soya because she had heard these beans were good for young children, and that she had successfully nursed her grandson back to health from severe malnutrition with frequent feeding of soy porridge. Grandmothers are also greatly affected by the added burden of HIV/AIDS in Malawi, and this burden affects their ability to care for young children as well as produce food. The grandmothers' caregiver role has increased with the high number of adults who have died of HIV (UNAIDS, 2006). This additional burden for women at the end of their childbearing years is an important part of their narrative. They are caring for their grandchildren while their own children have passed away, providing a stark reminder of the problems of the current era. Grandmothers in the participatory workshops expressed feelings of resentment, overwork and a lack of respect for traditional knowledge, linked to these broader social changes.

\section{Discussion}

The research results presented above and in other papers linked to this research (Bezner Kerr et al., 2007) suggest that the majority of women, despite active efforts by the hospital, continue to introduce foods to their babies at an early age. One of the reasons that women do not EBF is due to a long held view that women are not able to produce adequate amounts of breastmilk for babies, and that crying is a sign that children require 
additional foods. Earlier anthropological studies in Malawi noted that breastmilk was not considered adequate food for babies (Berry \& Petty, 1992; Read, 1959) and contemporary studies have found that mothers introduce other foods at a very early age (MSIS, 1996; Vaahter et al., 2001). Even if younger mothers disagree with this notion, or want to try feeding only breastmilk, they are often thwarted in their efforts to EBF by determined older women. These older women hold powerful positions within extended families and in the community in general, and are able to impose their childcare decisions on younger mothers. Older women feel that respecting their views in child feeding decisions is important for maintaining child health, and recognize that the hospital is actively opposing their stance. Many older women expressed the view that the high level of child malnutrition is due to a reduction in observance of traditional practices, particularly postpartum sexual abstinence, rather than exclusive breastfeeding. Many women expressed frustration with the EBF policy and felt that they had to appear to comply with hospital policies in order to obtain hospital services.

Grandmothers express strong opinions about early introduction of porridge and various root infusions to young babies, due to two key concepts: the inadequacy of breastmilk, and the dangers of promiscuity for young children's health. They view the changes in child malnutrition as linked to a changing society in which traditional practices are no longer respected. The concept of breastmilk being inadequate for young infants is common in many parts of the world (Caulfield et al., 1999), and considerable success has been made at working with mothers to change this perception (Green, 1999); what is lacking is a general effort to involve grandmothers in this dialogue. Given the important role that grandmothers play, at least in Malawi, actively involving them in nutrition education is one important change that could facilitate long-term effects on child nutrition. One of the few participatory research studies to involve grandmothers in a nutrition education program described a rapid change in grandmothers' views on EBF, along with other child feeding practices (Aubel et al., 2004). After being exposed to songs, dramas and stories that expressed respect for grandmothers and introduced different feeding practices in an open-ended way, the study reports $93 \%$ of 150 grandmothers advised $\mathrm{EBF}$, an increase from $29 \%$ the previous year.

The attitude of hospital staff, and their own views of EBF, need to be brought more openly into dialogue with grandmothers in order to effect change. Other studies have noted the tendency for medical staff to harangue patients over 'incorrect' feeding and health practices
(Ngubane, 1992; Zeitlyn \& Rowshan, 1997). The challenge for a participatory health and agriculture project is reconciling disparate and sometimes conflicting views over child feeding practices, and helping medical staff understand the perspectives of grandmothers. Establishing relationships of respect is one of the first steps needed if change is to occur, since an unequal relationship of power has led to the appearance of compliance with hospital policy, while early introduction of porridges and root infusions actually continued. Other programs that have actively solicited grandmother involvement and advocated a respectful view of their position have led to some success (Aubel \& Sihalathavong, 2001; Aubel et al., 2004) but these efforts largely ignored the difficult power dynamics that exist within extended families.

The results indicate that women face multiple constraints in feeding children frequently enough, particularly during the rainy season, and that grandmothers, who are often the other caregiver of young children, also have time and resource constraints that limit frequent feeding. In addition, grandmothers play a powerful, multifaceted role in their grandchildren's lives, including growing crops, caring for them and making feeding decisions. Younger women have very limited decisionmaking control over different care practices. SFHC project staff attempts to increase frequency of feeding and men's role in child feeding has been met with resistance by grandmothers, who view such efforts as another attack on their traditional roles, and resent the added workload imposed by frequent feeding of young children. Their powerful role within the extended family suggests that successfully addressing gender in this context will require taking their views, as well as those of younger women, into consideration. The tensions, contradictions and difficulties of addressing gender in this context make it more challenging than simply addressing the issues of women and men (Cornwall \& Gaventa, 2001).

\section{Conclusion}

There have been efforts to change feeding practices in Malawi since colonial times, but typically these efforts are done in a top-down way, not taking key decision-makers, particularly grandmothers', views into account. This paper examined power dynamics within households and between villages and the medical institutions that serve them. Child feeding and those involved in decision-making about child feeding cannot be addressed in isolation; this activity and the key social actors need to be considered in relation to their other roles in agriculture, decision-making, and their broader 
understanding of social change. The public health approach of 'teaching' mothers new knowledge about child feeding practices inadequately addresses these power dynamics, and ignores prevailing alternative explanations for child illness that exist in communities. The power and influence that grandmothers hold within an extended family has both negative and positive consequences, including a lack of respect for the workloads of younger women and early introduction of food sources to infants. The multiple roles of grandmothers in agriculture, child feeding and social relations within the household need to be considered in order to understand their perspectives on recommended child feeding practices and in order to find ways to incorporate their views while recognizing the inherent conflicts within the extended family and with medical institutions.

\section{Acknowledgements}

The authors gratefully acknowledge the contributions from participating farmers from the Soils, Food and Healthy Communities project of Ekwendeni Hospital, as well as Peter Berti, Angela Shonga, Tanya Trevors and David Ryan. The feedback from David Pelletier and Max Pfeffer on earlier drafts of this paper is also gratefully acknowledged.

\section{References}

Allen, L. H., \& Gillespie, S. (2001). What works? A review of the efficacy and effectiveness of nutrition interventions. Manila: Asian Development Bank.

Aubel, J. (2004). Generic steps in the grandmother-inclusive methodology. Chevy Chase, MD: The Grandmother Project.

Aubel, J., \& Sihalathavong, D. (2001). Participatory communication to strengthen the role of grandmothers in child health: an alternative paradigm for health education and health communication. Journal of International Communication, 7(2), 76-97.

Aubel, J., Toure, I., \& Diagne, M. (2004). Senegalese grandmothers promote improved maternal and child nutrition practices: the guardians of tradition are not averse to change. Social Science \& Medicine, 59(5), 945-959.

Barnes, J. A. (1959). The Fort Jameson Ngoni. In E. Colson, \& M. Gluckman (Eds.), Seven tribes of British Central Africa (pp. 194-252). Manchester: Manchester University Press.

Berry, V., \& Petty, C. (1992). The Nyasaland survey papers 19381943: Agriculture, food and health. London: Academy Books Ltd.

Bezner Kerr, R. (2006). Contested knowledge and disputed practice: Maize and groundnut seeds and child feeding in northern Malawi. Development Sociology. Ithaca, NY: Cornell University. p. 350.

Bezner Kerr, R., Berti, P., \& Chirwa, M. (2007). Breastfeeding and mixed feeding practices in Malawi: timing, reasons, decision makers, and child health consequences. Food and Nutrition Bulletin, 28(1), 90-99.

Bezner Kerr, R., \& Chirwa, M. (2004). Participatory research approaches and social dynamics that influence agricultural practices to improve child nutrition in Malawi. EcoHealth, 1 (Suppl 2), 109-119.

Caulfield, L. E., Huffman, S. L., \& Piwoz, E. G. (1999). Interventions to improve complementary food intakes of six to 12 month old infants in developing countries: impact on growth, prevalence of malnutrition, and potential contribution to child survival. Food and Nutrition Bulletin, 20, 183-200.

Coovadia, H. M., Rollins, N. C., \& Bland, R. M., et al. (2007). Mother-to-child transmission of HIV-1 infection during exclusive breastfeeding the first six months of life: an intervention cohort study. Lancet, 369, 1107-1116.

Cornwall, A., \& Gaventa, J. (2001). From users and choosers to makers and shapers: Repositioning participation in social policy[IDS Working Paper, 127].

Coutsoudis, A., Kuhn, L., Pillay, K., \& Coovadia, H. (2002). Exclusive breastfeeding and HIV transmission. AIDS, 16(3), 498-499.

Davies-Adetugbo, A. A. (1997). Sociocultural factors and the promotion of exclusive breastfeeding in rural Yoruba communities of Osun state, Nigeria. Social Science \& Medicine, 45(1), 113-125.

De Cock, K. M., Fowler, M. G., \& Mercier, E., et al. (2000). Prevention of mother-to-child HIV transmission in resource-poor countries. JAMA, 283(9), 1175-1182.

Engle, P., Bentley, M., \& Pelto, G. H. (2000). The role of care in nutrition research programmes: current research and a research agenda. Proceedings of the Nutrition Society, 59, 25-35.

Engle, P., Menon, P., \& Haddad, L. (1999). Care and nutrition: concepts and measurements. World Development, 27(8), 1309-1337.

van Esterik, P. (1995). Care, caregiving, and caregivers. Food and Nutrition Bulletin, 16(4), 378-387.

Gilchrist, V. J. (1992). Key informant interviews. In B. F. Crabtree, \& W. L. Miller (Eds.), Doing qualitative research (pp. 70-89). Newburg Park, CA: Sage.

Green, C. P. (1999). Interventions to improve breastfeeding behaviors: Detailed summaries of 51 studies. Washington, D.C.: Linkages.

Helitzer-Allen, D. L., Kendall, C., \& Wirima, J. J. (1997). Beliefs and practices during pregnancy in a Yao community in Malawi. In E. Kalipeni, \& P. Thiuri (Eds.), Issues and perspectives on health care in contemporary Sub-Saharan Africa (pp. 145-164). Lewiston: Edwin Mellen Press.

Hotz, C., \& Gibson, R. S. (2001). Complementary feeding practices and dietary intakes from complementary foods amongst weanlings in rural Malawi. European Journal of Clinical Nutrition, $55,841-849$.

Hotz, C., \& Gibson, R. S. (2005). Participatory nutrition education and adoption of new feeding practices are associated with improved adequacy of complementary diets among rural Malawian children: a pilot study. European Journal of Clinical Nutrition, 59, 226-237.

Iliff, P. J., Piwoz, E. G., \& Tavengwa, N. V., et al. (2005). Early exclusive breastfeeding reduces the risk of postnatal HIV-1 transmission and increases HIV-free survival. AIDS, 19, 699-708.

Kent, G. (1988). Nutrition education as an instrument of empowerment. Journal of Nutrition Education, 20, 193-195.

Lee, R. G., \& Garvin, T. (2003). Moving from information transfer to information exchange in health and healthcare. Social Science \& Medicine, 56, 449-464.

Lupton, D. (1995). The imperative of health: Public health and the regulated body. Thousand Oaks, CA: Sage.

Macharia, C. W., Kogi-Makau, W., \& Muroki, N. M. (2004). Dietary intake, feeding and care practices of children in Kathonzweni division, Makueni District, Kenya. East African Medical Journal, 81(8), 402-407. 
Madise, N. J., \& Mpoma, M. (1997). Child malnutrition and feeding practices in Malawi. Food and Nutrition Bulletin, 18(2), 190-201.

Maxwell, J. A. (1992). Understanding and validity in qualitative research. Harvard Educational Review, 62(3), 279-299.

Miles, M. B., \& Huberman, A. M. (1994). Qualitative data analysis: An expanded sourcebook. Thousand Oaks, CA: Sage.

MSIS. (1996). Malawi social indicators survey 1995: A survey into the state of health, nutrition, water and sanitation and education of children in Malawi. Zomba: Centre for Social Research.

Ngubane, H. (1992). Clinical practice and organization of indigenous healers in South Africa. In S. Feierman, \& J. M. Janzen (Eds.), The social basis of health and healing in Africa (pp. 366-375). Berkeley: University of California Press.

NSO, \& Macro. (1994). Malawi demographic and health survey 1992. Zomba, Malawi: Malawi National Statistical Office (NSO) and Macro International.

NSO, \& Macro. (2001). Malawi demographic and health survey 2000. Zomba, Malawi/Calverton, MD, USA: National Statistics Office and ORC Macro.

NSO, \& ORC Macro. (2005). Malawi demographic and health survey 2004. Zomba, Malawi/Calverton, MD, USA: National Statistical Office of Malawi (NSO) and ORC Macro.

Patton, M. Q. (1990). Qualitative evaluation and research methods. Newbury Park, CA: Sage.

Pelletier, D. (1994). The potentiating effects of malnutrition on child mortality: epidemiology, evidence and policy implications. Nutrition Reviews, 52, 409-415.

Pelto, G. H., Dicken, K., \& Engle, P. (1999). A critical link: Interventions for physical growth and psychological development. Geneva: World Health Organization.

Read, M. (1959). Children of their fathers. London: Metheun \& Co Ltd.

Ryan, G. W., \& Bernard, H. R. (2000). Data management and analysis methods. In Y. Lincoln, \& A. Guba (Eds.), Handbook of qualitative methods (pp. 771-797). Newbury Park: Sage.
Samba, K., Sy, M. N., Ntiru, M., \& Diene, S. M. (1999). Best practices and lessons learned for sustainable community nutrition programming. Washington, D.C.: BASICS/ORANA/SANA/ USAID.

Sear, R., Mace, R., \& McGregor, I. A. (2000). Maternal grandmothers improve nutritional status and survival of children in rural Gambia. Proceedings of the Royal Society of London - Biological Sciences, 267(1453), 1641-1647.

Shrestha, R. M. (1989). Breast-feeding and weaning practices in urban areas of Malawi. Lilongwe: Ministry of Health/UNICEF.

UNAIDS. (2006). 2006 Report on the global AIDS epidemic. Geneva: UNAIDS/WHO.

UNICEF. (2005). State of the world's children 2005. New York: UNICEF.

Vaahter, M., Kulmala, T., \& Hietanen, A., et al. (2001). Breastfeeding and complementary feeding practices in rural Malawi. Acta Paediatrica, 90, 328-332.

Waisbord, S. (2001). Family tree of theories, methodologies and strategies in development communication: Convergences and differences. New York: Rockefeller Foundation.

WHO. (1998). Complementary feeding of young children in developing countries: A review of current scientific knowledge. Geneva: World Health Organization.

WHO. (2003). HIV and infant feeding: Framework for priority action. Geneva, Switzerland: World Health Organization.

WHO, \& UNICEF. (2002). Global strategy for infant and child feeding. Geneva, Switzerland: World Health Organization.

Yoder, P. S. (1997). Negotiating relevance: belief, knowledge and practice in international health projects. Medical Anthropology Quarterly, 11(2), 131-146.

Zeitlyn, S., \& Rowshan, R. (1997). Privileged knowledge and mothers" "Perceptions": the case of breast-feeding and insufficient milk in Bangladesh. Medical Anthropology Quarterly, 11(1), 56-68. 